\title{
含异丙胺的 $\mathrm{Pt}^{(\mathrm{II})} 、 \mathrm{Pt}^{(\mathrm{IV})}$ 络合物的合成 及对 L-1210 的抑制作用
}

\author{
唐雯霞 郡荣泉 管荫桐 周爱萍 戴安邦 \\ (南京大学络合物化学研究所) \\ 籍秀娟方家濂 \\ (中国医学科学院药物研究所)
}

铂络合物的抗癌作用及其机理研究近年来很受重视, 但多数工作集中在二价铂络合物方 面, 对四价铂络合物的研究甚少. 最近发现反式二羟基二氯二异丙胺合铂 (IV) 具有较高水溶 性、较低的毒性以及和相应二价铂络合物的相近的抗癌活性 ${ }^{[1]}$, 反式二羟基丙二酸根二氨合铂 (IV $)^{[2]}$ 对 W-256 癌亦具有比顺式二氯二氨合铂(简称顺铂)高的治疗指数,均说明 $\operatorname{Pt}(\mathrm{IV})$ 络 合物抗癌作用是值得进一步深人研究的课题. 继前文 ${ }^{[2,3]}$ 我们进一步合成了六种含异丙胺的 $\mathrm{Pt}(\mathrm{II}) 、 \mathrm{Pt}(\mathrm{IV})$ 新络合物, 比较了它们的水溶性及对 $\mathrm{BDF}_{1}$ 小鼠的 L-1210 白血病的抑制作用, 发现反- $\left[\mathrm{Pt}^{(\mathrm{IV})}(\mathrm{i}-\mathrm{pr})_{2} \mathrm{Br}_{2}(\mathrm{OH})_{2}\right] \cdot \mathrm{H}_{2} \mathrm{O}$ 及反 $-\left[\mathrm{Pt}^{\mathrm{(IV)}}(\mathrm{i}-\mathrm{pr})_{2} \mathrm{ox}(\mathrm{OH})_{2}\right]$ 的水溶性和抗 $\mathrm{L}-1210$ 癌的能力均比相应的 $\mathrm{Pt}^{(\mathrm{II})}$ 络合物高, 尤其后一络合物的抗癌活性接近已临床应用的顺铂.

\section{络合物的合成和鉴定}

顺式二酸根二异丙胺合铂 $\left[\mathrm{Pt}^{(\mathrm{III})}(\mathrm{i}-\mathrm{pr})_{2} \mathrm{X}_{2}\right] \cdot n \mathrm{H}_{2} \mathrm{O}$ 和反式二羟基二酸根二异丙胺合铂 $\left[\mathrm{Pt}^{(\mathrm{IIV})}(\mathrm{i}-\mathrm{pr})_{2} \mathrm{X}_{2}(\mathrm{OH})_{2}\right] \cdot n \mathrm{H}_{2} \mathrm{O}\left(\mathrm{X}\right.$ 分别为 $\left.\mathrm{Cl}^{-} 、 \mathrm{Br}^{-} 、 \frac{1}{2} \mathrm{ox} 、 \frac{1}{2} \mathrm{mal}, n=0.1\right)$ 的合成步骤为

$$
\begin{aligned}
& \mathrm{K}_{2}\left[\mathrm{PtCl}_{6}\right] \frac{\mathrm{N}_{2} \mathrm{H}_{4} \cdot 2 \mathrm{HCl}}{70^{\circ} \mathrm{C} \text { 还原 }} \mathrm{K}_{2}\left[\mathrm{PtCl}_{4}\right] \stackrel{\mathrm{KI}}{\longrightarrow} \mathrm{K}_{2}\left[\mathrm{PtI}_{4}\right] \\
& \stackrel{\mathrm{i}-\mathrm{pr}}{\longrightarrow} \text { 顺 }-\left[\mathrm{Pt}(\mathrm{i}-\mathrm{pr})_{2} \mathrm{I}_{2}\right] \frac{\text { 计显 } \mathrm{AgNO}_{3}}{\text { 避光, } 25^{\circ} \mathrm{C}} \text { 顺 }-\left[\mathrm{Pt}(\mathrm{i}-\mathrm{pr})_{2}\left(\mathrm{H}_{2} \mathrm{O}\right)_{2}\right]\left(\mathrm{NO}_{3}\right)_{2} \\
& \stackrel{\mathrm{NaX} \text { 或 } \mathrm{KX}}{\longrightarrow} \text { 顺 }-\left[\mathrm{Pt}(\mathrm{i}-\mathrm{pr})_{2} \mathrm{X}_{2}\right] \cdot n \mathrm{H}_{2} \mathrm{O} \text {. }
\end{aligned}
$$

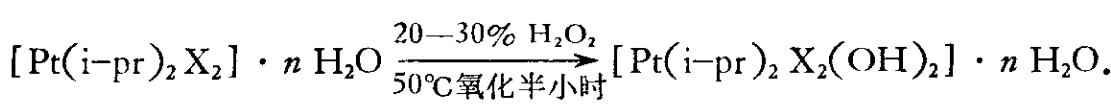

所得络合物在水中重结晶或用水、醇数次洗涤, 空气中或在 $\mathrm{P}_{2} \mathrm{O}_{5}$ 干燥器中干燥到恒重, 分析络 合物的 Pt、C、H 的含量, 在岛津 $\mathrm{IR}-27 \mathrm{G}$ 红外光谱仪上记录其红外光谱, 结果列于表 1 中.

由表 1 可见, 络合物的 $\mathrm{Pt} 、 \mathrm{C} 、 \mathrm{H}$ 元素分析结果和理论式量相符. 反式二羟基铂 (IV) 络 合物的红外光谱中, 在 $3400 \mathrm{~cm}^{-1}$ 左右出现配位羟基的伸缩振动峰, $1000 \mathrm{~cm}^{-1}$ 附近出现 $\mathrm{Pt}$ $\mathrm{OH}$ 的变形振动峰, 表明 $\operatorname{Pt}(\mathrm{IV})$ 络合物分子中确有配位羟基存在.

为确证络合物中结晶水的存在, 测定了含水络合物的差热和热失重曲线. 络合物失水温

本文 1981 年 7 月 27 日收到。 


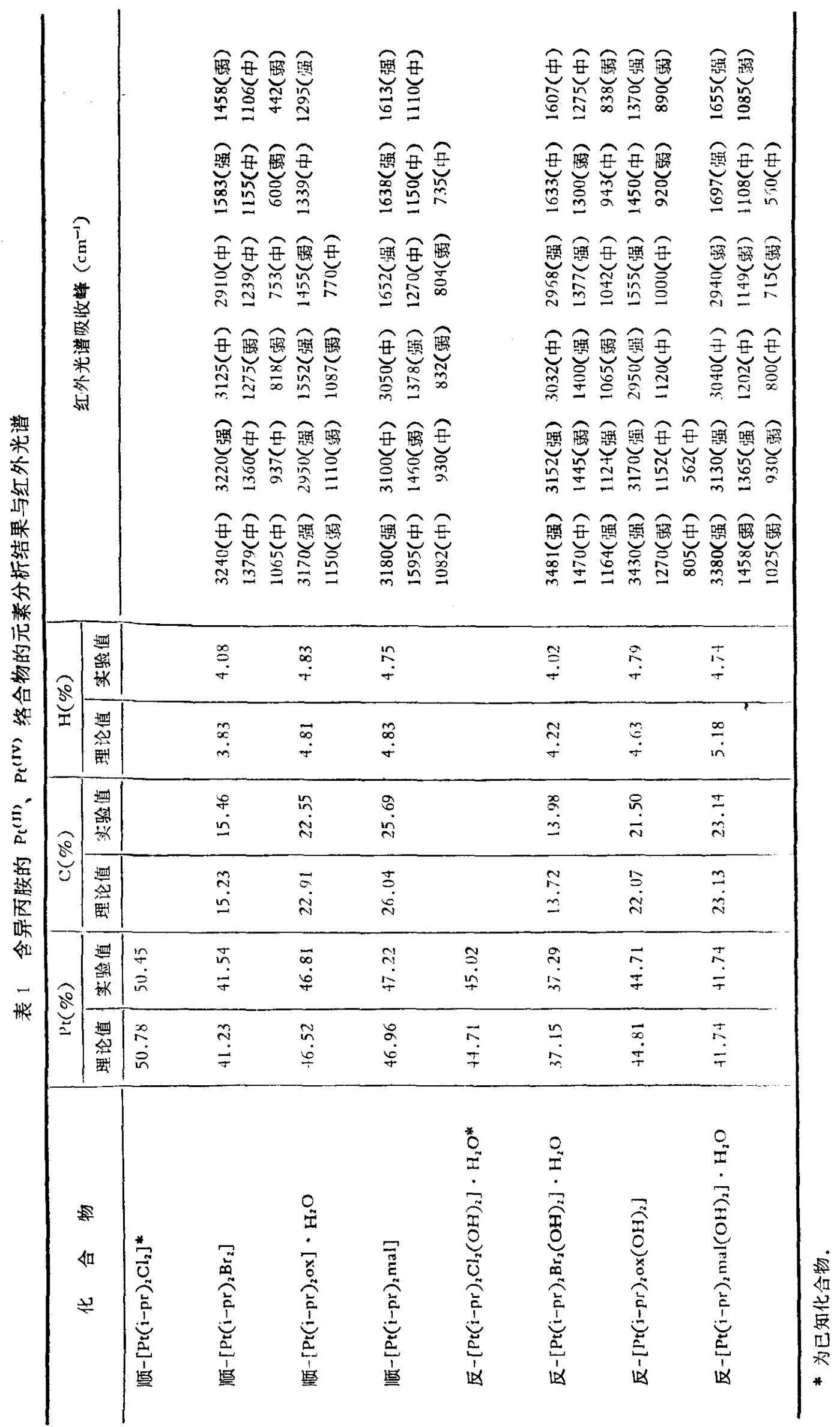


度, 相应温度下的失水重量以及理论失重列于表 2 中.

表 2 络合物失结晶水温度和失重百分数

\begin{tabular}{c|c|c|c}
\hline 分 子 式 & 失结晶水温度 ${ }^{\circ} \mathrm{C}$ & 失重 $(\%)$ \\
\hline$\left[\mathrm{Pt}(\mathrm{i}-\mathrm{pr})_{2} \mathrm{Ox}\right] \cdot \mathrm{H}_{2} \mathrm{O}$ & 153 & 理 论 值 & 实 测 值 \\
\hline$\left[\mathrm{Pt}(\mathrm{i}-\mathrm{pr})_{2} \mathrm{Br}_{2}(\mathrm{OH})_{2}\right] \cdot \mathrm{H}_{2} \mathrm{O}$ & 150 & 4.11 & 4.91 \\
{$\left[\mathrm{Pt}(\mathrm{i}-\mathrm{pr})_{2} \mathrm{mal}(\mathrm{OH})_{2}\right] \cdot \mathrm{H}_{2} \mathrm{O}$} & 129 & 3.43 & 11.71 \\
\hline
\end{tabular}

表 3 络合物的水溶解度 $\left(25^{\circ} \mathrm{C}\right)$

\begin{tabular}{c|c|c}
\hline 化 合 物 & 溶 \\
\hline$\left[\mathrm{Pt}(\mathrm{i}-\mathrm{pr})_{2} \mathrm{Br}_{2}\right]$ & 度 \\
\hline$\left[\mathrm{Pt}(\mathrm{i}-\mathrm{pr})_{2} \mathrm{Ox}\right] \cdot \mathrm{H}_{2} \mathrm{O}$ & 0.031 & $\mathrm{~m} M$ \\
{$\left[\mathrm{Pt}(\mathrm{i}-\mathrm{pr})_{2} \mathrm{mal}\right]$} & 0.218 & 0.65 \\
{$\left[\mathrm{Pt}(\mathrm{i}-\mathrm{pr})_{2} \mathrm{Br} r_{2}(\mathrm{OH})_{2}\right] \mathrm{H}_{2} \mathrm{O}$} & 3.94 & 5.20 \\
{$\left[\mathrm{Pt}(\mathrm{i}-\mathrm{pr})_{2} \mathrm{Ox}(\mathrm{OH})_{2}\right]$} & 0.855 & 94.9 \\
{$\left[\mathrm{Pt}(\mathrm{i}-\mathrm{pr})_{2} \operatorname{mal}(\mathrm{OH})_{2}\right] \cdot \mathrm{H}_{2} \mathrm{O}$} & 1.19 & 16.3 \\
\end{tabular}

反式二羟基二澳二异丙胺合铂水合物的热分解行为较为特殊, 其差热曲线于 $150^{\circ} \mathrm{C}$ 出现 强放热峰，相应的失重百分数为 $10.70 \%$ ，相当于失去三分子水的量. $150^{\circ} \mathrm{C}$ 失水前后化合物 红外光谱表明, 失重后样品光谱中, 原属于配位羟基伸缩振 动的吸收峰 $\left(3481 \mathrm{~cm}^{-1}\right)$ 及属于 $\mathrm{Pt}-\mathrm{OH}$ 变形振动的吸收峰 $\left(1043 \mathrm{~cm}^{-1}\right)$ 完全消失, 说明反 $-\left[\mathrm{Pt}(\mathrm{i}-\mathrm{pr})_{2} \mathrm{Br}_{2}(\mathrm{OH})_{2}\right] \cdot \mathrm{H}_{2} \mathrm{O}$ 在情性气氛中于 $150^{\circ} \mathrm{C}$ 除失去一分子结晶水外, 且有二个 $\mathrm{Pt}-\mathrm{OH}$ 键断裂而失去.

络合物在 $25^{\circ} \mathrm{C}$ 的水溶解度已经测定. 由表 3 可见, 反 式二差基 $\mathrm{Pt}(\mathrm{IV})$ 络合物的水溶性比相应 $\mathrm{Pt}$ (II) 络合物高 五倍以上. 其中尤以 $\left[\mathrm{Pt}^{(\mathrm{IV})}(\mathrm{i}-\mathrm{pr})_{2} \mathrm{mal}(\mathrm{OH})_{2}\right] \cdot \mathrm{H}_{2} \mathrm{O}$ 的水 溶性为最高,其值超过 10 克/100 毫升.

\section{络合物对 BDF 1 的 L-1210 的抑制作用}

取体重 18-23 克的雄性 $\mathrm{BDF}_{1}$ 小鼠 10-12. 只为一组, 腹腔接种 $1: 20 \mathrm{~L}-1210$ 腹水细胞液 0.2 毫升, 接种后第二 天按表 4 所列剂量一次腹腔注射络合物水溶液或吐温 80 为混悬剂的混悬液, 随即观察小鼠的平均生存天数、体重变

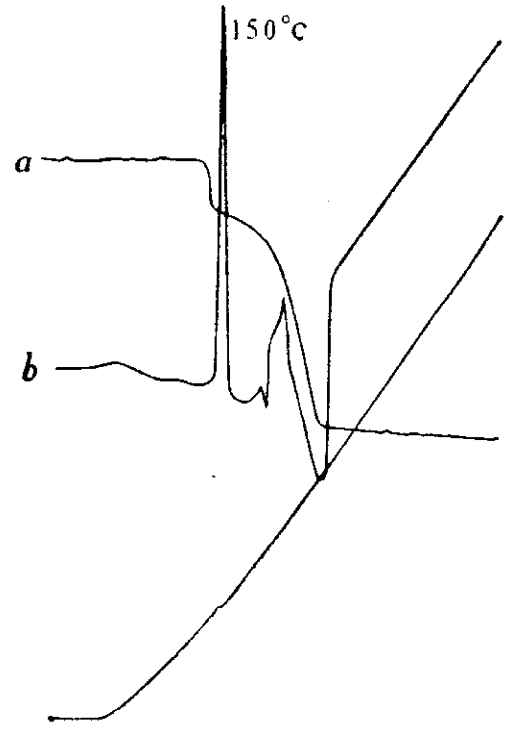

图 $1\left[\mathrm{Pr}(\mathrm{i}-\mathrm{pr})_{2} \mathrm{Br}_{2}(\mathrm{OH})_{2}\right] \cdot \mathrm{H}_{2} \mathrm{O}$ 的热失重 (a) 及差热曲线 (b) 化、寿命延长天数、延长百分率及 $P$ 值,结果列于表 4 .

顺- $\left[\mathrm{Pt}\left(\mathrm{NH}_{3}\right)_{2} \mathrm{Cl}_{2}\right]$ 在耐受剂量下 (4×1 毫克/公斤 ) 的延长百分率为 42.8 ,比文献值 $69 \%$ 或 $>64 \%$ 略低 ${ }^{[4]}$, 可能由于所用 $\mathrm{BDF}_{1}$ 小鼠的体质较差, 耐受剂量低于文献值 4.8 或 8 毫克/公 
斤引起. 含 $\mathrm{Br}^{-}, \mathrm{ox}^{2-}, \mathrm{mal}^{2-}$ 的三种 $\mathrm{Pt}^{(11)}$ 络合物在 $10 \times 1$ 剂量条件下的延长百分率均在 $30-$ $36 \%$ 之间, 活性显然比顺铂低. 四价铂络合物中反一 $-\left[\mathrm{Pt}\left(\mathrm{NH}_{3}\right)_{2} \mathrm{mal}(\mathrm{OH})_{2}\right] \cdot \mathrm{H}_{2} \mathrm{O}$ 的延长百分 率仅为 $19.0 \%$, 几无活性, 而在同样剂量条件下, 反- $\left[\mathrm{Pt}(\mathrm{i}-\mathrm{pr})_{2} \mathrm{Ox}(\mathrm{OH})_{2}\right]$ 和反一 $\left[\mathrm{Pt}(\mathrm{i}-\mathrm{pr})_{2}\right.$ $\left.\mathrm{Br}_{2}(\mathrm{OH})_{2}\right] \cdot 2 \mathrm{H}_{2} \mathrm{O}$ 的延长百分率分别为 $75.5 \%$ 和 $42.3 \%$, 比相 应的顺- $\left[\mathrm{Pt}(\mathrm{i}-\mathrm{pr})_{2} \mathrm{ox}\right]$ 、顺$\left[\mathrm{Pt}(\mathrm{i}-\mathrm{pr})_{2} \mathrm{Br}_{2}\right]$ 的延长百分率均高. 其中尤以反 $-\left[\mathrm{Pt}(\mathrm{i}-\mathrm{pr})_{2} \mathrm{ox}(\mathrm{OH})_{2}\right]$ 的抗癌活性较为突出, 甚 至比已在临床应用的顺铂在剂量为 $4 \times 1$ 毫克/公厅时的相应值高近一倍.

表 4 铂络合物抑制 L-1210 试验

\begin{tabular}{|c|c|c|c|c|c|c|c|c|c|}
\hline No. & 化 合 物 & 物理状态 & (毫克/公斤) & $\begin{array}{c}\text { 动物数 } \\
\text { 始/米(头) }\end{array}$ & $\begin{array}{l}\text { 平均生存 } \\
\text { 天数（天） }\end{array}$ & 体重変化 & $\begin{array}{c}\text { 延长天数 } \\
\text { (天) }\end{array}$ & 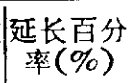 & $P$ 值 \\
\hline 1 & 顺 $-\left[\mathrm{Pt}(\mathrm{i}-\mathrm{pr})_{2} \mathrm{Br}_{2}\right]$ & 水混悬液 & $10 \times 1$ & $10 / 9$ & $>27.3$ & +8.3 & $>6.3$ & 30.0 & $<0.05$ \\
\hline 2 & $\|$ 顺 $-\left[\mathrm{Pt}(\mathrm{i}-\mathrm{pr})_{2} \mathrm{ox}\right] \cdot \mathrm{H}_{2} \mathrm{O}$ & 水混悬液 & $10 \times 1$ & $10 / 9$ & $>27.4$ & +6.3 & $>6.4$ & 30.4 & $<0.01$ \\
\hline 3 & 顺 $-\left[\mathrm{Pt}(\mathrm{i}-\mathrm{pr})_{2} \mathrm{mal}\right]$ & 水溶液 & $10 \times 1$ & $12 / 12$ & 19.5 & +13.0 & 5.2 & 36.3 & $>0.05$ \\
\hline 4 & 反 $-\left[\mathrm{Pt}(\mathrm{i}-\mathrm{pr})_{2} \mathrm{Br}_{2}(\mathrm{OH})_{2}\right] \cdot \mathrm{H}_{2} \mathrm{O}$ & 水混悬液 & $10 \times 1$ & $10 / 9$ & $>29.9$ & +8.3 & $>8.9$ & 42.3 & $<0.01$ \\
\hline 5 & 反 $-\left[\mathrm{Pt}(\mathrm{i}-\mathrm{pr})_{2} \mathrm{ox}(\mathrm{OH})_{2}\right]$ & 水溶液 & $10 \times 1$ & $12 / 12$ & 25.1 & +13.2 & 10.8 & 75.5 & $<0.01$ \\
\hline 6 & 反 $-\left[\mathrm{Pt}\left(\mathrm{NH}_{3}\right)_{2} \operatorname{mal}(\mathrm{OH})_{2}\right] \cdot \mathrm{H}_{2} \mathrm{O}$ & 水混悬液 & $10 \times 1$ & $10 / 9$ & $>25.1$ & +9.0 & $>4.1$ & 19.0 & $>0.05$ \\
\hline \multirow[t]{3}{*}{7} & 顺 $-\left[\mathrm{Pt}\left(\mathrm{NH}_{3}\right)_{2} \mathrm{Cl}_{2}\right]$ & 水混悬液 & $4 \times 1$ & $10 / 8$ & $>30$ & +3 & $>9$ & 42.8 & $<0.01$ \\
\hline & 对照组 (1) & - & - & $10 / 9$ & 21 & +19 & - & - & - \\
\hline & 对照组 (2)* & - & - & $12 / 12$ & 14.3 & +12.6 & - & - & - \\
\hline
\end{tabular}

*No.3、5 二络合物的对照组.

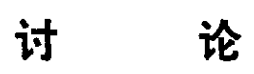

一般认为 Pt(II) 络合物的抗癌功能的必要结构条件是具有一对位于顺式的影响络合物脂 溶性的氨或胺分子配体, 另一对位于顺位的具有中等离解能力或易为体内代谢作用的一价或 二价酸根配体所组成的电中性络合物, 从而保证络合物透过细胞膜, 并有效的和靶分子 DNA 链的碱基作用, 产生链内或链间交联而使癌细胞 DNA 的复制发生障碍 ${ }^{[5]} \operatorname{Pt}(\mathrm{IV})$ 络合物由 于取代反应十分缓慢 ${ }^{[6]}$, 认为只有通过体内还原成相应的 $\operatorname{Pt}\left(\right.$ II) 络合物才显示其抗癌活性 ${ }^{[7]}$, 因此它们的抗癌活性一般比相应 Pt(II) 络合物低或相近似 ${ }^{[1,7]}$. 但是此种四价铂络合物抗癌作 用的体内还原机制显然不能解释本文所发现的反 $-\left[\mathrm{Pr}^{\mathrm{IV}}(\mathrm{i}-\mathrm{pr})_{2} \mathrm{ox}(\mathrm{OH})_{2}\right]$ 和反 $-\left[\mathrm{Pt}^{\mathrm{IV}}(\mathrm{i}-\mathrm{pr})_{2}\right.$ $\left.\mathrm{Br}_{2}(\mathrm{OH})_{2}\right] \cdot \mathrm{H}_{2} \mathrm{O}$ 具有比相应的 $\left[\mathrm{Pt}^{\mathrm{II}}(\mathrm{i}-\mathrm{pr})_{2} \mathrm{Ox}\right]$ 和 $\left[\mathrm{Pt}(\mathrm{i}-\mathrm{pr})_{2} \mathrm{Br}_{2}\right]$ 较高的抗 $\mathrm{L}-1210$ 白血病能 力. 本文的结果表明, $\mathrm{Pt}^{(\mathrm{IV})}$ 的抗癌作用可能具有不同于 $\mathrm{Pt}^{\mathrm{II}}$ 的作用机制. 最近已有人发现, 当 $\mathrm{Pt}^{(\mathrm{II})}$ 络合物与 $\mathrm{DNA}$ 体外作用时, 导致 $\mathrm{DNA}$ 分子构型发生变化, 而当 $\mathrm{Pt}^{(\mathrm{IV})}$ 络合物作用 时却造成 DNA 链的断裂 ${ }^{[8]}$. 总之四价铂络合物的抗癌作用及其作用机制是需要急待弄清的 问题, 反 $-\left[\mathrm{Pt}^{\mathrm{IV}}(\mathrm{i}-\mathrm{pr})_{2} \mathrm{ox}(\mathrm{OH})_{2}\right]$ 的抗癌作用正在进一步研究中.

\section{参考文献}

[1] Tobe, L. M., Khokhar, A. R., J. Clin. Hematol. Oncol., 1 (1977), 114.

[2]倍雯霞、管荫柌、郡荣泉、戴安邦等, 科学通报, 26(1981), 10: 633 .

「3] 潘启超、刘宗潮、谢水芬等, 科学通报, 25(1980), 14: 662 .

[ 4 ] Burchenal, J. H., Kalaher, K., Dew, K. \& Lokye, L., Cancer Treat. Rep., 63 (1979), 1493.

[ 5$]$ Cleare, M. J., Coord. Chem. Rev., 12 (1974). 349.

[6] Hartley, F. R., The Chemistry of Platinum \& Palladium, Appl. Sci. Pub. Ltd. 1973, 315.

[7] Beaumont, K. P., MeAuliffe, C. A. \& Cleare, M. J., Chem. Biol. Interactions, 14 (1976), 179.

[8] Mong, S., Prestayko, A. W. \& Crooke, S. T., C. A., $93(1980), 88856$ N. 